\title{
Design of Neuro-Fuzzy Controller for Stabilization of Single Phase Stand-Alone PV Power System
}

\author{
Hitendra Singh Thakur, Ram Narayan Patel \\ ${ }^{1}$ Departement of Electrical and Electronics Engineering, SSTC-SSITM, (C.G), India
}

\begin{tabular}{l}
\hline \hline Article Info \\
\hline Article history: \\
Received Feb 8, 2018 \\
Revised Jul 5, 2018 \\
Accepted Aug 5, 2018 \\
\hline
\end{tabular}

Keyword:

Adaptive neuro fuzzy inference system (ANFIS)

Single phase

Stand-alone Photo Voltaic (PV) system

Synchronous Reference Frame (SRF)

Voltrage Source Inverter (VSI)

\begin{abstract}
For the three phase power electronic and drive applications, vector control or the synchronous reference frame (SRF) based control concept is well accepted and settled amongst the research communities. Although the SRF concept has gained popularity and appreciation in developing the three phase controllers, still the concept has not reached the same level in case of a single phase system. The work presented in this paper is mainly concerned to the design of a hybrid Artificial Neural Network and Fuzzy Logic based controller for a single phase stand-alone photo-voltaic (PV) power system. The adaptive neuro fuzzy inference system (ANFIS) controller proposed in this paper is chiefly meant for improving the transient and steady state responses; for minimizing the distorting effect of the low order load current harmonics encountered particularly in case of switching the drive based inductive loads and to help maintain the inverter output voltage constant under different loading circumstances. The result obtained through simulation work, shows the effectiveness of the proposed controller as compared with the previously established research works.
\end{abstract}

Copyright (C) 2018 Institute of Advanced Engineering and Science. All rights reserved.

\section{Corresponding Author:}

Hitendra Singh Thakur

Departement of Electrical and Electronics Engineering, SSTC-SSITM, (C.G), India

Email: thakurhitendrasingh@gmail.com

\section{INTRODUCTION}

The ever increasing demand of electrical power from various newer avenues and increase intake of power due to the expansion policies of different existing installations have put a threat on the conventional fuel reserves (like fossil fuels). On the other-hand the increasing global concern over atmospheric pollution, followed by the governmental policies of decreasing Carbon Oxides and Nitrogen Oxides emission, have opened avenue for development of Distributed Generation (DG) plants based particularly on nonconventional sources of energy like Wind power and Solar Power. The power generation capacities of these DGs are limited hence these are connected usually to low voltage distribution lines. The power generated by the DG plants need to made fit for utilization before it is fed to cater the local loads in case of stand-alone power system or when it is connected to utility grid in case of grid connected system. Power electronic converters have played an important role in conditioning of power for their better utilization [1,2].

In the stand-alone mode of operation, the inverters are required to maintain the voltage and frequency essentially constant at the consumer's terminal so as to ensure the system stability and satisfactory transient performance. There are various control methodologies reported in different literatures regarding the inverter control, operating in stand-alone mode. These control schemes, as reported in the literatures, are as: the repetitive control [3-7], that deals particularly with the periodic signals and is effective in mitigating the waveform distortion caused by harmonics. This control technique suffers from its incapability to deal with the disturbances which are aperiodic in nature and besides that it also claims large memory for its functionality. Model predictive control (MPC) and dead beat control work on simple concept and provides 
relatively faster transient response. For correct prediction and proper operation, the scheme requires an accurate converter model. The robust control (H-infinity control) technique, although capable of providing a good balance between system performance and stability margin, the two desirable but incompatible features of the system, suffers the difficulty of not being implemented on digital processors also they possess complexity in their design specifications [8-12]. The nonlinear controller, such as sliding mode controllers, possess good dynamic performance capability and can effectively prevent over-shoot in the inverter output voltage waveform, but it suffers from the issue of sensitivity towards the variation of the system parameters. Many software-algorithm based parameter estimation techniques have been developed and proposed in different literatures, which help in effectively reducing the measurement circuits from the hardware section $[13,14]$. The proportional-resonant (PR) controllers proved superior in getting rid of steady state error related to the tracking problem of ac signals. The synchronous reference frame proportional- integral (SRFPI) controller has reported a widespread application where zero steady state error is desired. The scheme can be successfully applied to both three phase as well as single phase inverter system. The conventional control strategies mostly require the thorough knowledge of the system and are based on that development of mathematical model of the system to be controlled [15-22]. To avoid the inherent undesirable characteristics of conventional control approaches, fuzzy logic based control methods have been developed. A fuzzy logic based close loop current controller does not depend on the accurate machine parameters and neither is it affected by the nonlinearity present in the machine and the drive [23-24].

In present work, focuses in designing an adaptive neuro-fuzzy logic based synchronous reference frame (ANFIS-SRF) controller for controlling the PWM input to the single phase inverter which is employed for stand-alone PV application. The objective of the controller is to maintain the inverter output voltage constant, within the permissible tolerance range under different loading environment, in order to achieve transient and steady state stability. The system comprises of a Photovoltaic system, a dc to dc boost converter, a single phase voltage source inverter and different single phase domestic loads. The rule base prepared for the ANFIS controller is an outcome of the detailed and minute analysis of the inverter output voltage and current changes which are subject to different load conditions. The proposed controller is designed in MATLAB/Simulink environment.

\section{RESEARCH METHOD}

The overall system can be broadly divided into six sections as shown in Figure 1. The first section comprises of a dc source which consists of a photo voltaic panel supported by ultra-capacitor bank. The ultracapacitor support renders the output voltage of the PV system almost constant. The second section is a dc to dc step up converter with a dc link capacitor at its output terminals. The third section comprises of a single phase bridge inverter constructed from four insulated gate bipolar junction transistor, IGBT switches. An LC filter circuit is provided at the load terminals of the inverter. The fourth section comprises of the sinusoidal pulse width modulation SPWM generation unit which generates pulses to control the IGBTs and hence the inverter output. Fifth section is the Load unit where different loads are programmed to switched in for different interval of time in order to test the performance of the proposed system. The sixth section is the controller section which consists of adaptive fuzzy logic inference system, a phase locked loop block, an ab0 to dq0 transformation block, a dq0 to ab0 block, comparator etc.

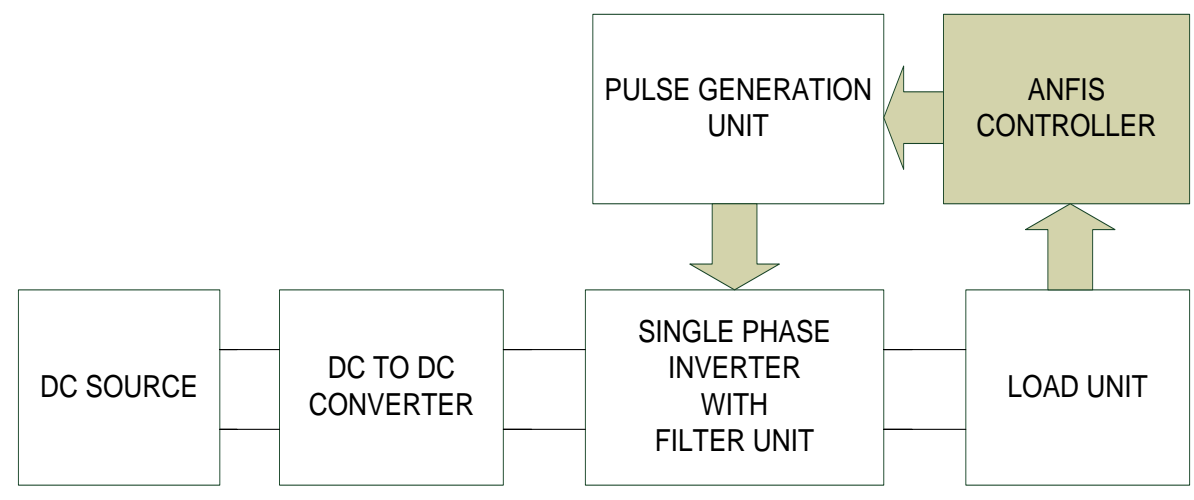

Figure 1. System Block Representation 


\subsection{Operation of the System}

The output of the Solar PV system, is fed to a step up dc to dc converter which steps up the voltage and the output dc link capacitor maintains it constant. The output of the DC converter is fed to the single phase inverter. To make the inverter voltage sinusoidal an LC filter is connected in between the inverter output and the load terminals. The load section is comprised of both linear and non-linear loads which are switched into the system at the appropriate interval of time.

As shown in the Figure 2 four IGBTs are connected in bridge topology to form the inverter circuit, $\mathrm{L}_{\mathrm{f}}$ and $\mathrm{C}_{\mathrm{f}}$ are the filter components. The load terminal voltage at the point of common coupling is measured and, with proper processing, fed to the ab0 to dq0 converter, the $\mathrm{V}_{\mathrm{d}}$ (direct axis component) so obtained is compared with the reference voltage $V_{\text {dref }}$ which is obtained from the dc link at the input of the inverter. The comparator output is a voltage error signal which along with the rate of change of the error signal is fed to the ANFIS controller. The output of ANFIS controller is used to modify the modulation index of the SPWM generation unit.

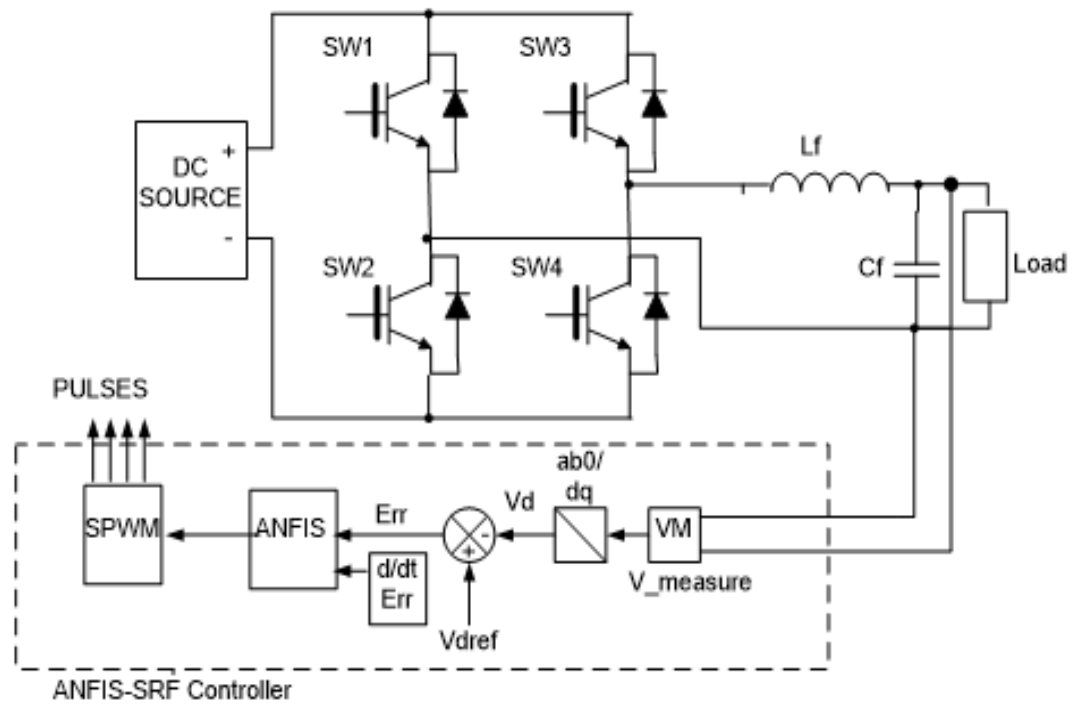

Figure 2. Circuit description

\section{CONTROLLER DESIGN}

The three phase VSI offers three degrees of freedom which are (a) the modulation index; (b) the phase angle; and (c) the frequency. In this work we are interested in developing a single phase standalone system in which our main concern is the modulation index. In the proposed ANFIS controller, there are two input variables and one output variable. Error (Err) and the rate of Change of Error (CErr) derived from the measured voltage signal at the point of common coupling as shown in Figure 3, are selected as the input variables while the output variable is the required control signal for adjusting the width of the sinusoidal pulses, by varying the modulation index.

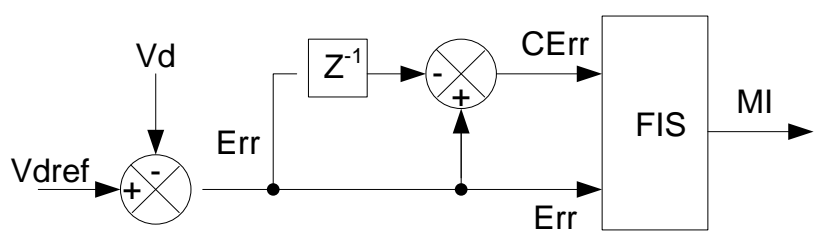

Figure 3. Input and output structure of Fuzzy Inference System (FIS)

Here, (1-2) 


$$
\begin{aligned}
& \text { Err }=V_{d r e f}-V_{d} \\
& \text { CErr }=\text { Err }-\frac{d}{d t} \text { Er }
\end{aligned}
$$

The adaptive neuro fuzzy hybrid system offers the advantageous common features of both the techniques and the fuzzy logic system. The present work uses following steps to develop the controller. Firstly, an FIS is developed with five membership functions for each of the two inputs and an output. The system is then made to run and the error data set, change in the error data set and the data set of the corresponding output from the controller is sent to the MATLAB work space. In the next step, the ANFIS is invoked and with work space dataset, it is trained.

The neural network is used to generate the new membership functions for the ANFIS controller. The newly trained and developed ANFIS is now used in place of FIS controller. The system is again made to run and the process of collecting the dataset is repeated and ANFIS is re trained using inbuilt back propagation optimization method. The newly trained system is checked and validated for the inputs and output and is put to service. The initially designed FIS is inputted with the error signal 'Err' and the rate of change of error 'CErr' are each sectored for 5 degrees of membership functions as shown in (3-4).

$$
\begin{aligned}
& \text { Err }=\left\{E_{\mathrm{NL}}, \mathrm{E}_{\mathrm{NS}}, \mathrm{E}_{\mathrm{Z}}, \mathrm{E}_{\mathrm{PS}}, \mathrm{E}_{\mathrm{PL}}\right\} \\
& \mathrm{CErr}=\left\{\mathrm{CE}_{\mathrm{NL}}, \mathrm{CE}_{\mathrm{NS}}, \mathrm{CE}_{\mathrm{Z}}, \mathrm{CE}_{\mathrm{PS}}, \mathrm{CE}_{\mathrm{PL}}\right\}
\end{aligned}
$$

The range of the Err is from $\{0-150\}$ where excess 0.5 unit is kept to accommodate the over voltage effect. Similarly, the range of second input variable CErr is from $\{-2$ to +2$\}$. The output variable 'MI' of the controller has 5 linguistic variables or membership functions as shown in (5), i.e.

$$
\mathrm{MI}=\left\{\mathrm{MI}_{\mathrm{NL}}, \mathrm{MI}_{\mathrm{NS}}, \mathrm{MI}_{\mathrm{Z}}, \mathrm{MI}_{\mathrm{PS}}, \mathrm{MI}_{\mathrm{PL}}\right\}
$$

Triangular membership functions are chosen on account of its feasible presentation and effective result in present particular case. The fuzzy rules for the FIS controller is tabulated as shown in Table 1. It is a five cross five rule matrix with linguistics named as NL-negative large, NS-negative small, Z-zero, PS-positive small, PL-positive large. The membership functions are so selected and arranged to have a control output which should maintain the voltage within prescribed limits under all loading conditions.

Table 1. FIS Rules for Voltage Control

\begin{tabular}{ccccccc}
\hline \multirow{2}{*}{ MI } & \multicolumn{5}{c}{ Err } \\
\cline { 3 - 7 } & & $\boldsymbol{E}_{N L}$ & $\boldsymbol{E}_{N \boldsymbol{N}}$ & $\boldsymbol{E}_{\boldsymbol{Z}}$ & $\boldsymbol{E}_{\boldsymbol{P S}}$ & $\boldsymbol{E}_{\boldsymbol{P L}}$ \\
\hline \multirow{4}{*}{ CErr } & $\boldsymbol{C} \boldsymbol{E}_{N L}$ & $M I_{N L}$ & $M I_{N L}$ & $M I_{N L}$ & $M I_{N S}$ & $M I_{Z}$ \\
& $\boldsymbol{C} \boldsymbol{E}_{N S}$ & $M I_{N L}$ & $M I_{N L}$ & $M I_{N S}$ & $M I_{Z}$ & $M I_{P S}$ \\
& $\boldsymbol{C} \boldsymbol{E}_{\boldsymbol{Z}}$ & $M I_{N L}$ & $M I_{N S}$ & $M I_{Z}$ & $M I_{P S}$ & $M I_{P L}$ \\
& $\boldsymbol{C} \boldsymbol{E}_{\boldsymbol{P S}}$ & $M I_{N S}$ & $M I_{Z}$ & $M I_{P S}$ & $M I_{P L}$ & $M I_{P L}$ \\
& $\boldsymbol{C} \boldsymbol{E}_{\boldsymbol{P L}}$ & $M I_{Z}$ & $M I_{P S}$ & $M I_{P L}$ & $M I_{P L}$ & $M I_{P L}$ \\
\hline
\end{tabular}

\subsection{Neural Network for generating Fuzzy Inference System}

The neural network is the integral part of the ANFIS. The ANFIS is trained with dataset produced by the preliminary developed FIS. The neural network next generates the new FIS and this ANFIS is placed in the control system for further interaction with system. The neural network avoids the repetition in tuning and is adaptable to variation in the system parameters through self-adjusting property. The neurons are an important part of the neural network which does all the mathematical computational work. Weights and bases with threshold values and reference values help in modification of the input parameters. The learning of the ANFIS is the supervised learning which incorporated backpropagation of error with each epoch (fixed time interval). The ANFIS structure is shown in the Figure 4. Training of the network is an essential step for selection of the appropriate rules for generating a control signal. Figure 5, shows the ANFIS structure with 5 interconnected network layers described as follows. 


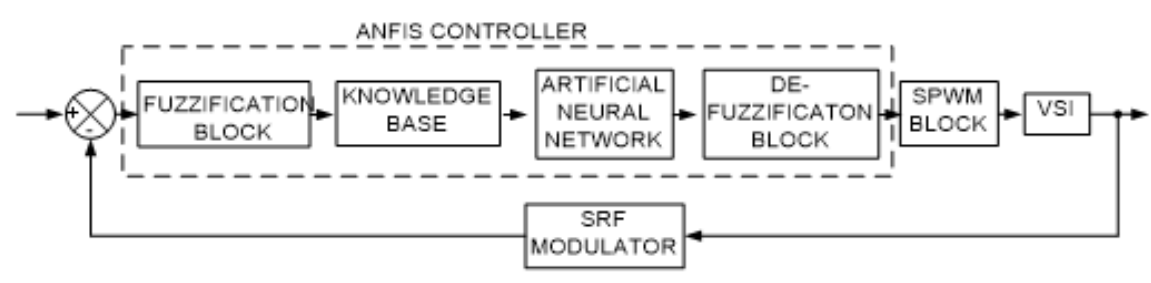

Figure 4. Block representation of VSI system with controller

Layer $1(l=1)$ this layer is the input layer which consist of input membership functions (MFs), viz., Err and CErr. The input layer 1 is a layer with two nodes that supplies the input values to the next layer. The membership function is specified by (6):

$$
\operatorname{Triangle}(x ; p, q, r)=\left\{\begin{array}{cc}
0, & x \leq p \\
\frac{x-p}{q-p}, & p \leq x \leq q \\
\frac{r-x}{r-q}, & q \leq x \leq r \\
0, & r \leq x
\end{array}\right\}
$$

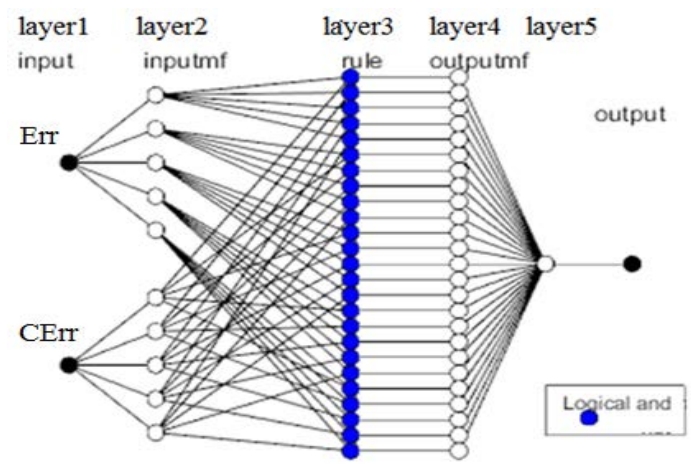

Figure 5. ANFIS Structure

The above equation can also be represented by (7) using min and max expression.

$$
\operatorname{Triangle}(x ; p, q, r)=\max \left(\min \left(\frac{x-p}{q-p}, \frac{r-x}{r-q}\right), 0\right)
$$

Here the $\{\mathrm{p}, \mathrm{q}, \mathrm{r}\}$ is the parameter set where $\mathrm{r}>\mathrm{q}>\mathrm{p}$ forms the three vertices of the triangular membership functions. Every node which belongs to this layer has an adaptive feature. The node function associated with the response of the node can be represented as shown in (8-9):

$$
\begin{aligned}
& \mathrm{R}_{\mathrm{l}, \mathrm{n}}=\alpha_{\mathrm{E}_{\mathrm{n}}}(\mathrm{Er}), \quad \text { for } \mathrm{n}=1 \text { to } 5 \\
& \mathrm{R}_{\mathrm{l,n}}=\alpha_{\mathrm{CE}_{\mathrm{n}-5}}(\mathrm{CEr}), \quad \text { for } \mathrm{n}=6 \text { to } 10
\end{aligned}
$$

here, $\mathrm{l}=$ layer number; $\mathrm{n}=$ node number; $\alpha=$ membership function

Layer $2(l=2)$ this layer, known as membership layer, checks the weights of each MF. It receives the input values from $1^{\text {st }}$ layer and acts as MFs to represent the fuzzy sets of the respective input variables. The output of every node (which is a fixed node) in this layer is the product of all incoming signals to the particular node. The output can be represented as shown in (10):

$$
\mathrm{R}_{\mathrm{l}, \mathrm{n}}=\mathrm{W}_{\mathrm{n}}=\alpha_{\mathrm{E}_{\mathrm{n}}}(\mathrm{Er}) \times \alpha_{\mathrm{CE}_{\mathrm{n}}}(\mathrm{CEr}), \quad \text { for } \mathrm{n}=1,2, . .
$$


Each node output represents the strength of firing of a rule.

Layer $3(l=3)$ this layer executes the following function for pre-processing of the fuzzy rules, like they calculate the triggering level of each rule, the number of layers and the number of fuzzy rules being equal. Each node of this layer evaluates the normalized weights. The ${ }^{\text {th }}$ node calculates the ratio of nth rule's triggering strength to the sum of firing strengths of all the rules as shown in (11).

$$
\mathrm{R}_{\mathrm{l}, \mathrm{n}}=\overline{\mathrm{W}_{\mathrm{n}}}=\frac{\mathrm{W}_{\mathrm{n}}}{\Sigma_{1}^{\mathrm{n}} \mathrm{W}_{\mathrm{n}}}
$$

The output of this layer is called normalized firing strengths.

Layer $4(l=4)$ this layer delivers the output values ensuing from the implication of rules. Connections between the layers 13 and 14 are weighted by the fuzzy singletons that represent another set of parameters for the neuro-fuzzy network. Every node in this layer is an adaptive node with a node function as shown in (12):

$$
\mathrm{R}_{4, \mathrm{n}}=\overline{\mathrm{W}_{\mathrm{n}}} \mathrm{F}_{\mathrm{n}}=\overline{\mathrm{W}_{\mathrm{n}}}\left(\mathrm{S}_{\mathrm{n}} \mathrm{Er}+\mathrm{T}_{\mathrm{n}} \mathrm{CEr}+\mathrm{U}_{\mathrm{n}}\right)
$$

Where, $\overline{W_{n}}$ is a normalized firing strength from layer 3 and $\left\{S_{n}, T_{n}, U_{n}\right\}$ are the consequent parameter set of this node.

Layer $5(l=5)$ this layer is called the output layer, which computes the overall output as the summation of all the inputs coming from layer 4 and transforms the fuzzy classification results into a crisp (binary). The output of each node in the layer can be defined by (13):

$$
\mathrm{R}_{5, \mathrm{n}}=\sum \overline{\mathrm{W}_{\mathrm{n}}} \mathrm{F}_{\mathrm{n}}=\frac{\Sigma_{\mathrm{n}} \mathrm{W}_{\mathrm{n}} \mathrm{F}_{\mathrm{n}}}{\Sigma_{\mathrm{n}} \mathrm{W}_{\mathrm{n}}}
$$

Artificial Neural Network, possesses the ability of strong learning while the Fuzzy logic is capable of interpreting the control data and integrate with the knowledge base. The hybridization of the two schemes is known to be the adaptive neuro fuzzy inference system ANFIS, that utilizes the merits of both the systems.

\section{SIMULATION RESULTS AND DISCUSSIONS}

The proposed ANFIS controller backed by SRF modulation is implemented in

\begin{tabular}{|c|c|}
\hline DC Source & Solar PV Panel: Vout $=50 \mathrm{~V}$; Irradiation $-1000 \mathrm{~W} / \mathrm{m}^{2} ;$ Temp $=25^{\circ} \mathrm{C}$. UC Bank: 50V \\
\hline $\begin{array}{l}\text { DC-DC Converter } \\
\text { For PV and UC }\end{array}$ & $\begin{array}{l}\text { Vout }=200 \mathrm{~V}(\mathrm{dc}) \text {; Duty Ratio, } \delta=0.62 \text {; Carrier Frequency SPWM, fc }=10 \mathrm{kHz} \text {; Line inductor, } \\
\text { L=15uH; DC Link, C=22uF }\end{array}$ \\
\hline DC-AC Inverter & $\begin{array}{r}\text { Vout=200V(ac); Carrier Frequency, fc }=10 \mathrm{kHz} \text {; SPWM Frequency of modulating signal, } \\
\mathrm{fm}=50 \mathrm{~Hz}\end{array}$ \\
\hline Filter & $\begin{aligned} & \mathrm{L}_{\mathrm{f}}=5.2 \mathrm{mH} ; \mathrm{C}_{\mathrm{f}}=67 \mathrm{uF} \\
& \mathrm{L} 1=4 \mathrm{KW} ; \mathrm{L} 2=8 \mathrm{KW} ; \mathrm{L} 3=12 \mathrm{KW} ; \mathrm{L} 4=15 \mathrm{KW}\end{aligned}$ \\
\hline
\end{tabular}
MATLAB/SIMULINK and the system parameters are as shown in Table 2.

Table 2. Simulation Parameters

The results obtained from simulation indicates the efficient working of the proposed control scheme. Figure 6 shows the simulation results of load voltage V, load current I with the voltage waveform before filter unit. Different loads are applied at the simulation time of $0.1 \mathrm{sec}$., $0.2 \mathrm{sec}$., $0.3 \mathrm{sec}$. The loads are sequentially increased as can be observed by the waveform of current which is increasing every time as the load is being changed. The controller maintains constant voltage across the load of 200V. Controller is also accommodating the effects of transients at the instants of switching hence rendering the system dynamically stable. The controller output is the function of the modulation index (MI) and from the combined waveform it can be observed that as the load is increasing the controller is changing the modulation index so as to maintain the voltage at the load terminals constant.

Since the time varying (sinusoidal) signals are rather difficult to control than the time in-varying (dc) signals hence in the proposed scheme a single phase ab0 to dq0 transformation block is used to convert ac signal into its dc equivalent the method of transformation is based on the Park's transformation method. Figure 7 shows the simulation result of the direct and quadrature axis load voltage and current wave forms. It is evident from the waveform that it is easy for the controller to detect the changes taking place in $V_{d}$ and $I_{d}$ on account of varying the load. 

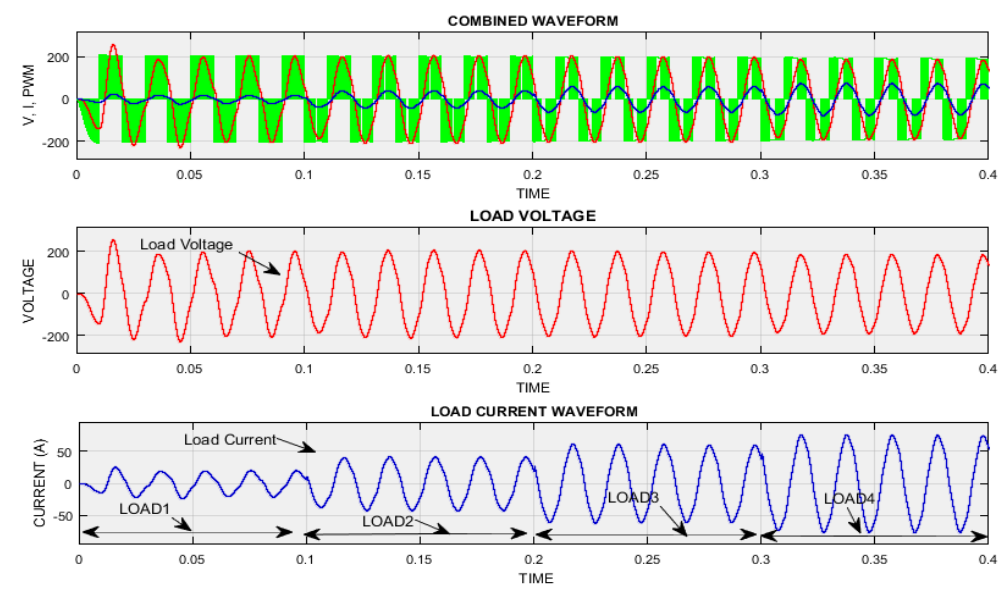

Figure 6. Load Voltage and Current waveform post ANFIS training
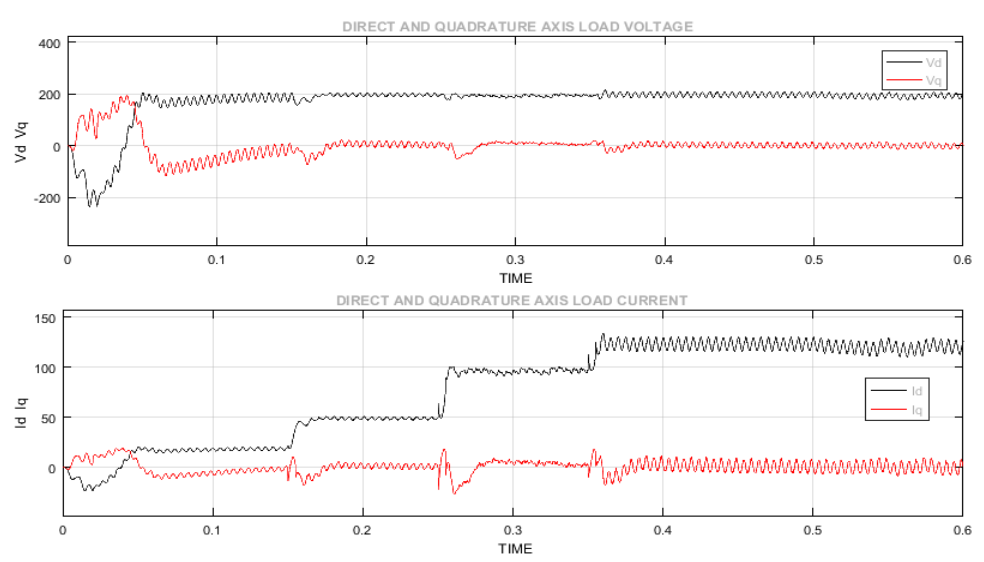

Figure 7. $\mathrm{d}$ and $\mathrm{q}$ axis voltage and current waveforms post ANFIS training

The FFT analysis of the waveforms presented in Figures 8 and 9 give the information of the total harmonic distortion present in the load voltage and current waveforms is about $1.05 \%$ which is within the acceptable limit as per the power quality norms.
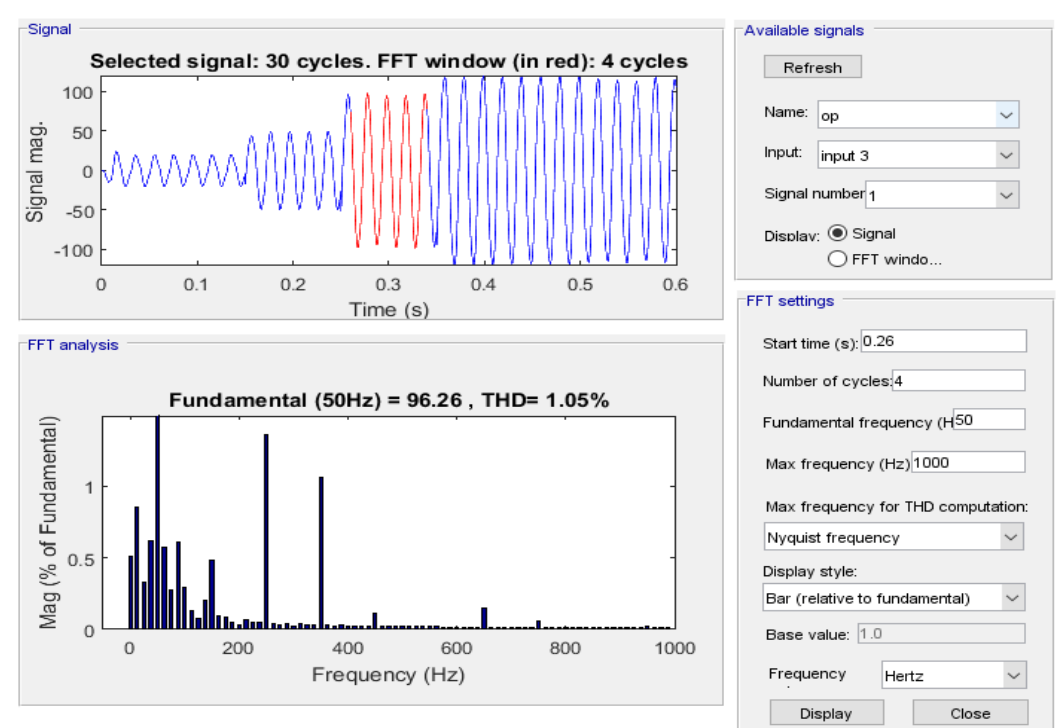

Figure 8. Load current FFT 

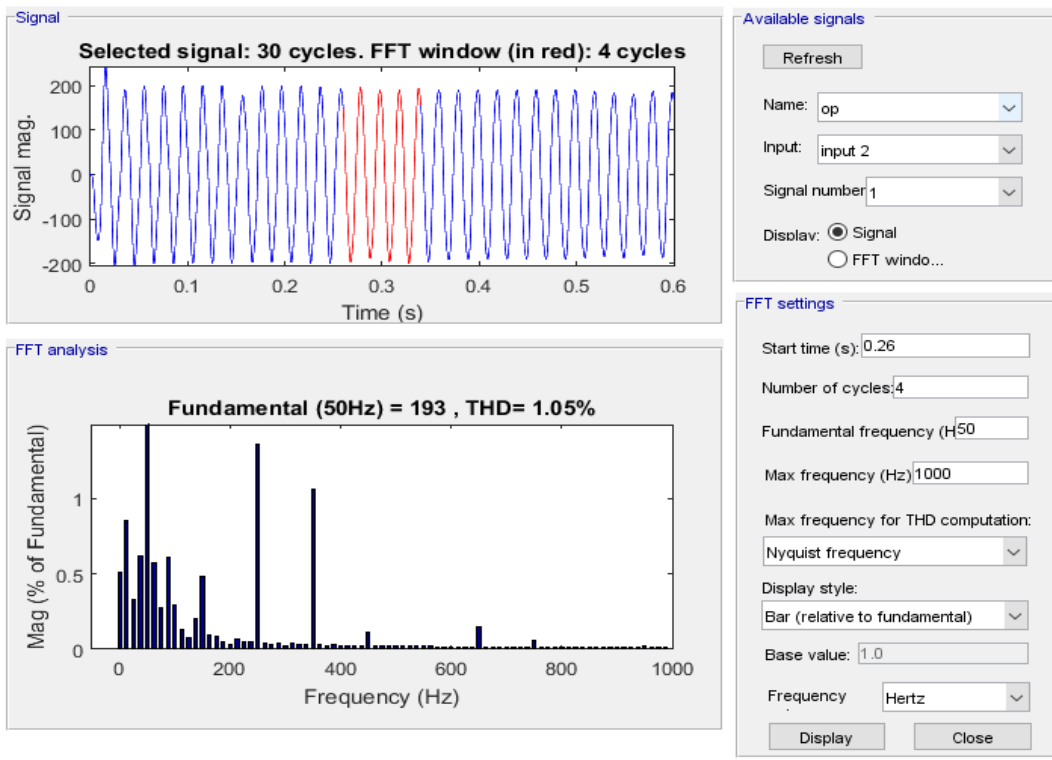

Figure 9. Load voltage FFT

\section{CONCLUSION}

The present work proposes an ANFIS controller for maintaining the load terminal voltage of a VSI, employed to a stand-alone PV power system, within the prescribed limits (essentially constant) under different load changing circumstances. As compared with the various effective controllers like PID controller, the neuro-fuzzy based controller has resulted in maintaining the load terminal voltage constant under varying load circumstances and hence ensuring the steady state and dynamic stability. The results obtained from experimental setup developed for investigating the performance of the controller have also validated the success of the controller operation in comparison with the PI controller. The advantages of the proposed converter are its time saving feature and the control methodology not involving complex mathematical procedure.

\section{REFERENCES}

[1] J.M. Ortega, et.al., "VSC-based Topologies to Further Integrate Renewable Energy Sources in Distribution Systems”, IET Renew. Power Gen., 2012, 6, (6), pp. 435-445.

[2] M. Monfared, et.al., “Analysis, Design, and Experimental Verification of a SRF-VC for 1-phase Inverter”, IEEE Trans. Ind. Elect., 2014, 61, (1), pp.258-269.

[3] F. Blaabjerg, et.al., "Power Electronics Converters for Wind Turbine Systems”, IEEE Trans. Ind. Appl., 2012, 48, (2), pp.708-719.

[4] M. Monfared, et.al., "Direct Active and Reactive Power Control of Single-phase Grid-tie Converters", IET Power Electron., 2012, 5, (8), pp. 1544-1550.

[5] R. Oruganti, et.al., "A Control Method for High-performance UPS Inverters Through Output-impedance Reduction”, IEEE Trans. Ind. Electron., 2008, 55, (2), pp. 888-898.

[6] A. Lidozzi, et.al., "Resonant-repetitive Combined Control for Stand-alone Power Supply Units", IEEE Trans. Ind. Appl., 2015, 51, (6), pp. 4653-4663.

[7] T. Liu, et.al., "Parallel Structure Fractional Repetitive Control for PWM Inverters", IEEE Trans. Ind. Electron., 2015, 62, (8), pp. 5045-5054.

[8] Y. Chen, et.al., "Robust Predictive Dual-loop Control Strategy with Reactive Power Compensation for Single-phase Grid-connected Distributed Generation System”, IET Power Electron., 2013, 6, (7), pp. 1320-1328.

[9] H.R. Karshenas, et.al., "Hybrid Learning Control Strategy for Three-phase Uninterruptible Power Supply", IET Power Electron., 2011, 4, (7), pp. 799-807.

[10] S. Kwak, et.al., "Model Predictive Control Methods to Reduce Common-mode Voltage for 3-ph VSI", IEEE Trans. Power Electron.,2015, 30, (9), pp. 5019-5035.

[11] J.S. Lim, C. Park, J. Han, et al., "Robust Tracking Control of a Three-phase DC-AC Inverter for UPS Applications", IEEE Trans. Ind. Electron., 2014, 59, (1), pp. 4142-4151.

[12] T.S. Lee, et.al., "Robust Controller Design for a 1-phase UPS Inverter Using $\mu$-synthesis", Proc. Inst. Electr. Eng. Electr. Power Appl., 2004, 151, (3), pp. 334-340.

[13] H. Komurcugil, et.al., "An Extended Lyapunov-function-based Control Strategy for Single-phase UPS Inverters”, IEEE Trans. Power Electron., 2015, 30, (7), pp. 3976-3983. 
[14] R. Razi, M. Monfared, "Simple Control Scheme for Single-phase Uninterruptible Power Supply Inverters with Kalman Filter-based Estimation of the Output Voltage”, IET Power Electron., 2015, 8, (9), pp. 1817-1824.

[15] Li, Y.W., "Control and Resonance Damping of Voltage-source and Current-source Converters with LC Filters", IEEE Trans. Ind. Electron., 2009, 56, (5), pp. 1511-1521.

[16] Wai, R.J., et.al., "Design of BS control for high-performance inverter with stand-alone and grid-connected powersupply modes”, IET Power Electron., 2013, 6, (4), pp. 752-762.

[17] A. H. Zadeh, et.al., "Multi-loop Linear Resonant VSI Controller Design for Distorted Loads Using the Linear Quadratic Regulator Method”, IET Power Electron., 2012, 5, (6), pp. 841-851.

[18] Vandoorn, T.L., et.al., "Theoretical Analysis and Experimental Validation of 1-phase Direct vs. Cascade Voltage Control in Islanded Micro-grids”, IEEE Trans. Ind. Electron., 2013, 60, (2), pp. 789-798.

[19] C. Zou, et.al., "Stationary Frame Equivalent Model of Proportional-integral Controller in dq Synchronous Frame”, IEEE Trans. Power Electron., 2014, 29, (9), pp. 4461-4465.

[20] D.Simon, "Kalman Filtering with State Constraints: a Survey of Linear and Nonlinear Algorithms”, IET Power Electron., 2010, 4, (8), pp. 1303-1318.

[21] E. Ghadimi, et.al., "Multi-step Gradient Methods for Networked Optimization”, IEEE Trans. Signal. Proc., 2013, 61, (21), pp. 5417-5429.

[22] H. Akagi, “Active Harmonic Filters,” Proceeedings IEEE, vol. 93, pp.2128-2141, 2005.

[23] N. Altin, et.al., “dSPACE based Adaptive Neuro-fuzzy Controller of Grid Interactive Inverter,” Energy conservation and management, vol. 56, pp.130-139, 2012.

[24] S. K. Jain, P. Agrawal, H. O. Gupta, "Fuzzy Logic Controlled Shunt Active Filter for Power Quality Improvement," IEE Proceedings: Electric Power Applications, vol. 149, pp. 317-328, 2002.

\section{BIOGRAPHIES OF AUTHORS}

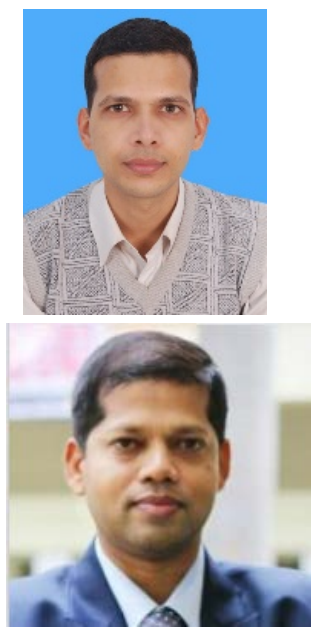

Mr. H S Thakur pursed BE in Electrical Engineering from RGPV University Bhopal, M.P, India in 2005 and Master of Engineering from CSVTU University in 2012. He is currently pursuing Ph.D. and working as Assistant Professor in Department of Electrical and Electronics Engineering, SSTC-SSITM, Bhilai, C.G. since 2008. His main research work focuses on Power Electronics converter development for Solar PV systems, Hybridization of multiple sources. He has 10 years of teaching experience and 4 years of Research Experience.

Mr R N Patel pursed BE in Electrical Engineering from SGSITS, Indore, M.P. India in 1997 and and M.Tech and PhD from IIT Delhi in 1999 and 2003 respectively. Dr. Patel has served as faculty in the Electrical Engineering Department at IIT Roorkee (year 2003 to 2006) and at the Birla Institute of Technology and Science (BITS), Pilani (year 2003). Currently, he is Professor in the Department of Electrical and Electronics Engineering, Shri Shankaracharya Technical Campus (SSTC), Bhilai (CG), India. He is a Senior member of IEEE. He has published more than 40 research papers in reputed international journals and conferences including IEEE. He has also authored a Book, 'Programming in MATLAB- A Problem Solving Approach' with Pearson in the year 2014. His main research work focuses on dynamic and steady state analysis of different components of Power Systems, FACTS devices, Control Systems and Power system protection. He has 15 years of teaching and Research Experience. 